\title{
Relação médico-doente: uma aliança nos cuidados de saúde
}

Ana Cristina Pereira,* Filipa Alves Rocha**

\section{RESUMO}

Introdução: Os motivos que levam um utente a recorrer aos cuidados de saúde e a forma como valoriza os sintomas e os perceciona como problema vão depender da história pessoal e do contexto familiar, cultural e socioeconómico. A «doença do doente» (illness) e a «doença do médico» (disease) são termos usados para descrever o que «o doente sente quando vai ao médico» e «o que ele tem quando volta para casa após a consulta». Este caso pretende realçar a importância do motivo de consulta e da sua exploração pelo Médico de Família (MF).

Descrição do Caso: Homem, 56 anos, desempregado. Separado, família unitária. Recorreu à consulta, pela primeira vez nos últimos quatro anos, por lesão no antebraço com cinco anos de evolução. Registo de consulta em 2007 com diagnóstico de hipertensão arterial mas negava antecedentes relevantes. Fumador, consumo moderado de álcool, não fazia medicação. Verificou-se tensão arterial (TA) elevada e lesão tumoral vegetativa, do tipo couve-flor, no antebraço. Aceitou reiniciar cuidados de saúde, pediu-se estudo analítico e referenciou-se para dermatologia. Diagnóstico posterior de carcinoma espinocelular. Voltou à consulta para mostrar resultados. Perante a possibilidade de ser diabético o doente desvalorizou. Confirmou-se o diagnóstico e mantendo TA elevada propôs-se anti-hipertensor, anti-diabético oral e anti-dislipidémico, a que o utente aderiu.

Comentário: O MF deve tentar perceber o porquê do doente ter recorrido apenas agora aos cuidados de saúde. Medo de ser rotulado de doente? Pela rede social ser escassa? Este paciente, que até então se considerava saudável, foi rotulado com um problema/doença diferente em cada consulta. Compete ao MF fazer a gestão das suas expectativas, que devem ser exploradas, discutidas e negociadas, para que os cuidados prestados sejam mais efetivos e melhor aceites pelo paciente, o que terá implicações na adesão terapêutica e satisfação com este encontro.

Palavras-chave: Relação Médico-Doente; Motivo de Consulta; Doença; Dolência.

\section{INTRODUÇÃO}

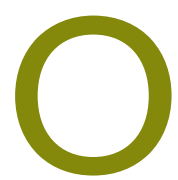

$\mathrm{s}$ motivos que levam os utentes a recorrer ou não aos cuidados de saúde são muito variáveis. Mesmo quando existem sinais ou sintomas, estes podem não ser valorizados pelo indivíduo no sentido de o fazer consultar o seu médico ou tomar a iniciativa de "se tratar». A forma como o indivíduo perceciona o problema e valoriza os sintomas como sendo doença vai depender da sua história pessoal e do seu contexto familiar, cultural e socioeconómico. Quando um ou mais sintomas são classificados como doença e a rede social de apoio (família, amigos, vizinhos) do indivíduo confirma esse diag-

\footnotetext{
*Interna de Medicina Geral e Familiar/ USF Nova Via, ACES Grande Porto VIII Espinho/Gaia

**Interna de Medicina Geral e Familiar/ USF Egas Moniz, ACES Entre Douro e Vouga I - Feira/Arouca
}

nóstico, poderá ser necessário que seja rotulado de doente e tal exige que esteja disposto a aceitar esse papel e que se tomem medidas, recorrendo a algum dos setores do sistema local de saúde. Segundo Kleinman ${ }^{1}$, este é definido como um conjunto de recursos que existem numa determinada comunidade para responder às situações de doença, dividindo esse sistema em três setores: popular, «folk» e profissional. No setor popular estão incluídos os auto-cuidados, os cuidados prestados pela família, vizinhos e amigos e a rede social de apoio em geral. Os especialistas locais, como por exemplo os «endireitas», curandeiros, etc., e alguns representantes de medicinas alternativas (acupuntura, homeopatia, etc.) pertencem ao setor "folk». Os médicos, enfermeiros e outros representantes de medicina complementar estão incluídos no setor profissional.

Quando um doente procura o médico tem já alguma ideia sobre o seu problema de saúde, que advém da 
sua experiência, cultura local e da rede social de apoio. Frequentemente, esse mesmo doente já tentou algumas soluções terapêuticas e seguiu uma cadeia de conselhos, desde auto-medicação, família, amigos, vizinhos e farmacêutico. ${ }^{2}$ O médico está geralmente apenas no final desta cadeia. A decisão de recorrer a este irá depender ainda da disponibilidade dos cuidados médicos e da capacidade económica para os suportar. Assim, o doente só irá recorrer ao médico quando ele e aqueles ao seu redor se sen-

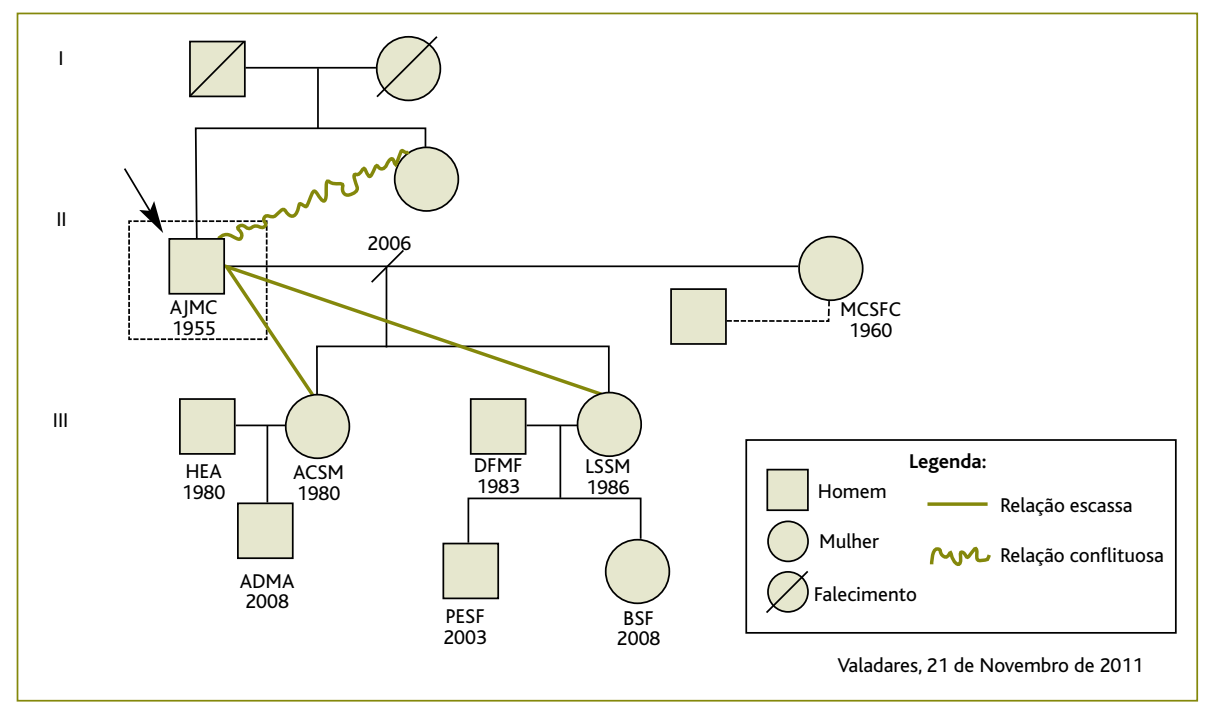

Figura 1. Genograma familiar e psicofigura de Mitchel. tem incapazes de lidar com o

problema, perante a falha do tratamento «popular» e/ou quando atinge o seu limiar de ansiedade ou tolerância. Quando este encontro entre o médico e o doente acontece, dá-se também o encontro entre duas perspetivas diferentes, que devem ser esclarecidas, discutidas e negociadas em cada consulta. Como auxílio nesta abordagem é importante ter em consideração as diferenças entre as definições «leigas» $\mathrm{e}$ «médicas» do que é a saúde, bem como o conceito de «doença do doente» (illness) e de «doença do médico» (disease). $\mathrm{O}$ termo «illness» é usado para classificar o que «o doente sente quando vai ao médico» e a palavra «disease» para descrever «o que ele tem quando volta para casa após a consulta com o médico»., $\mathrm{O}$ conceito de dolência deve também ser tido em conta, isto é, os efeitos psicossociais da doença, a dor e o sofrimento que a doença/problema causa àquele doente. Alguns autores consideram que numa consulta devem ser avaliadas quatro dimensões da dolência: os medos e sentimentos relacionados com o problema, as explicações acerca das queixas/problema, o impacto do problema na vida diária e as expectativas do doente face ao médico. ${ }^{3}$ Este caso pretende realçar a importância da perspetiva do doente sobre o problema de saúde que o levou a procurar o seu médico (motivo da consulta) e compreender a diferença entre «illness» $\mathrm{e}$ «disease» como auxílio na abordagem em Medicina Geral e Familiar (MGF) e na relação estabelecida desde o primeiro con- tacto com o Médico de Família (MF).

\section{DESCRIÇÃO DO CASO}

Apresenta-se o caso de um doente, o Sr. José (nome fictício), sexo masculino, 56 anos de idade, ex-empregado de armazém (desempregado), com o quarto ano de escolaridade. Separado há cinco anos. Tinha duas filhas, casadas e com filhos. Pertencia a uma família unitária. Vivia num anexo da casa da irmã com a qual mantinha relação conflituosa. A relação com as filhas foi sempre distante mas agravou-se desde a separação (Figura 1).

«Nunca gostou de ir ao médico» (sic). Tinha «medo de estar doente», «de tirar sangue» (sic). Ia à consulta sempre acompanhado pela esposa ou pelas filhas, o que deixou de acontecer após a separação. Consequentemente cessou de procurar e manter os cuidados de saúde.

\section{2/Maio/2011 - 1. a consulta}

Recorreu a uma consulta em maio de 2011, pela primeira vez nos últimos quatro anos, por iniciativa própria. O motivo de consulta foi uma lesão no antebraço, com cerca de cinco anos de evolução, crescimento gradual e atualmente pruriginosa. "Não percebia de onde vinha aquela lesão» mas "como não incomodava..." (sic). Começou a preocupar-se pelas hemorragias frequentes associadas e decidiu marcar consulta por pressão dos vizinhos. 
No processo clínico informatizado constava apenas o registo de uma consulta em 2007, ainda com a anterior MF, à qual terá recorrido por se sentir doente. Nessa consulta estava registado o diagnóstico de hipertensão arterial (HTA), tendo sido medicado com losartan $50 \mathrm{mg}$ id, e na lista de problemas acrescia o abuso do tabaco, abuso crónico do álcool e doença do fígado não especificada.

Quando questionado pela atual MF, negava antecedentes cirúrgicos, internamentos e até mesmo antecedentes patológicos, incluindo HTA. Não fazia medicação regular e negava alergias conhecidas. Mantinha hábitos tabágicos (20 cigarros/dia) e consumo moderado de álcool (336 g/semana). Negava consumo de drogas de abuso, fazia uma alimentação sem restrições e não praticava qualquer exercício físico. Dos antecedentes familiares, apenas a referir história de alcoolismo do pai. Neste contacto com o Sr. José foi avaliada a tensão arterial (TA). Perante valores de 160/95 mmHg, o doente continuou a negar ser hipertenso. Apresentava, ainda, índice de massa corporal (IMC) de $27,3 \mathrm{~kg} / \mathrm{m}^{2}$ e uma lesão tumoral, vegetativa, do tipo couve-flor, no antebraço direito. Discutiu-se o plano proposto com o doente, que aceitou reiniciar cuidados de saúde e fazer estudo analítico. Explicou-se a probabilidade de se confirmar o diagnóstico de HTA, pediram-se análises e programou-se uma consulta de seguimento. Foram tiradas fotografias da lesão e enviadas pelo TRIAD (Triagem Rápida com Imagem À Distância), projeto do Serviço de Dermatologia do Centro Hospitalar de Vila Nova de Gaia/Espinho para abreviar o processo de referenciação. Obteve-se resposta após cinco dias úteis com marcação de consulta de dermatologia. Nesta foram colocadas as hipóteses diagnósticas de carcinoma espinocelular ou verruga vírica de grandes dimensões e agendada a exérese da lesão.

\section{1/julho/2011 - 2. ${ }^{\text {a }}$ consulta}

Voltou na consulta programada para mostrar os resultados dos meios complementares de diagnóstico pedidos. Fez referência à marcação da cirurgia pela dermatologia e falou, discretamente, dos problemas familiares com as filhas e com a ex-mulher.

Reavaliou-se a TA (150/80 mmHg), com confirmação do diagnóstico de HTA. Analiticamente, apresentava alterações de parâmetros indicadores de consumo ex- cessivo de álcool (Volume globular médio 100,3 fL, Gama GT 196 U/L e TGO 43 U/L), hiperglicemia em jejum (Glicose $162 \mathrm{~g} / \mathrm{dL}$ ) e Colesterol total $235 \mathrm{mg} / \mathrm{dL}$, HDL Colesterol $67 \mathrm{mg} / \mathrm{dL}$, Triglicerídos $98 \mathrm{mg} / \mathrm{dL}$ (LDL Colesterol 148,4). Colocou-se a hipótese de diagnóstico de diabetes mellitus tipo 2 (DM2), da qual o doente desconfia, afirmando «não posso ser diabético porque não como açúcar!» (sic).

Atualizou-se a lista de problemas, acrescentando dislipidemia e hiperglicemia. Negociou-se novamente o plano com o doente e tentou-se integrar a agenda do doente com a do técnico. Discutiu-se a importância das alterações e o papel do Sr. José no controlo das mesmas. Verificou-se que estava disposto a esclarecer o diagnóstico de DM2 mas ainda não aceitava medicação por não se sentir doente. Optou-se por pedir a Prova de Tolerância à Glicose Oral (PTGO) com 75 gramas, para envolver o doente no processo de consciencialização do diagnóstico de DM2.

\section{5/julho/2011 - 3. ${ }^{\text {a }}$ consulta}

Veio a consulta não programada, nesse mesmo mês, para mostrar o resultado. Perante PTGO positiva (Glicemia às $0 \mathrm{~h}=173 \mathrm{~g} / \mathrm{dL}$ e às $2 \mathrm{~h}=406 \mathrm{~g} / \mathrm{dL}$ ), TA de $175 / 114$ mmHg e IMC de $27,3 \mathrm{~kg} / \mathrm{m}^{2}$, explicaram-se as inerências e as possíveis complicações de cada diagnóstico e a importância de cumprir a medicação, alterar estilos de vida e manter uma vigilância periódica em consulta. Propôsse iniciar anti-hipertensor (ramipril $5 \mathrm{mg}$ ), anti-diabético oral (metformina $850 \mathrm{mg}$ com aumento gradual da dose) e anti-dislipidémico (sinvastatina $20 \mathrm{mg}$ ); o doente pareceu aceitar. Marcou-se consulta de vigilância, para um mês depois, para avaliar a adesão à terapêutica, eventuais efeitos laterais e fundamentalmente a adaptação à sua nova condição. Voltaria o Sr. José à consulta?

\section{Consultas seguintes}

Sim, regressou à consulta programada (26/08/2011 $-4 .{ }^{a}$ consulta) e demonstrou confiança na sua MF queixando-se de disfunção erétil, temática muitas vezes considerada tabu. Percebia que tinha doenças que necessitavam de acompanhamento e que não teriam sido detetadas se não fossem investigadas, pois sentia-se saudável.

Objetivamente apresentava TA controlada (135/85 $\mathrm{mmHg}$ ), tinha perdido quatro quilogramas (IMC $=25,8$ 
$\mathrm{kg} / \mathrm{m}^{2}$ ) e o estudo analítico mostrava uma Hemoglobina Glicosilada de 7,2\%. Felicitou-se o doente pelas mudanças no estilo de vida e alterações conseguidas e incentivou-se a sua manutenção.

Na consulta seguinte $(21 / 11 / 2011)$, o doente referiu que se «emociona» (sic) sempre que vem à consulta por saber que tem ali «uma pessoa que se preocupa com a sua saúde» (sic). E até ele começou a interessar-se pela mesma, questionando sobre o problema que teve no braço, uma vez que «ninguém lhe tinha dito o que era...» (sic). Tinha uma ótima adesão à terapêutica farmacológica instituída, apesar de manter os consumos de álcool e tabaco e de não realizar exercício físico. Referiu «estar melhor» (sic) da disfunção erétil e falou novamente da sua ex-família, talvez uma das suas maiores preocupações. Agora vinha sozinho às consultas, «teve que se desenrascar» (sic) sem o apoio das filhas. Mas sempre que vem à consulta vem «nervoso e com medo» (sic). Pela relação de confiança estabelecida com a sua MF, que esclareceu as suas dúvidas e receios, este medo já não se relacionava com a sua saúde mas sim com a possibilidade de encontrar a ex-mulher ou filhas, utentes da mesma MF.

\section{COMENTÁRIO}

Neste caso, o doente recorreu ao seu MF por sua iniciativa, por considerar que a lesão do antebraço, que continuava a crescer desde há cinco anos, não era normal. O MF deve tentar perceber o porquê de ter recorrido à consulta apenas agora. Pelo medo de ser rotulado de doente? Pela sua rede social de apoio ser escassa? Este doente que vivia sozinho, sem contacto com a família, desempregado e por isso sem colegas de trabalho e, aparentemente, sem amigos, não tinha uma rede social de apoio que o incentivasse a procurar ajuda e, talvez por isso, não valorizasse o seu problema. Não havendo resolução da lesão, verificando até um agravamento pela hemorragia (sinal que habitualmente alarma os doentes) e com a insistência dos vizinhos para marcar consulta, o doente terá atingido o seu limiar de tolerância, sem contudo se mostrar muito preocupado com a sua possível origem. Apenas com a continuidade das consultas e a relação estabelecida com a sua MF, o Sr. José foi-se lentamente capacitando dos seus problemas e da importância de cumprir o plano de tratamento acordado para a sua resolução.
Motivos de consulta são as razões expressas pelo paciente para justificar a procura de cuidados médicos. A pergunta-chave, numa fase inicial da consulta, é «por que é que este doente veio consultar-me hoje?» Os motivos ou razões para o encontro dependem da perceção do paciente do seu estado de saúde bem como das suas expectativas. Esta clarificação inicial das ideias e expectativas do doente, quer em relação a si quer em ralação à atuação do médico, é fundamental para uma melhor negociação do plano e concordância com os objetivos e metas a atingir. ${ }^{4,5}$ Compete assim ao MF identificar e clarificar o motivo de consulta, tal como foi expresso pelo paciente, sem juízos de valor, explorar esse motivo e as ideias prévias sobre o seu problema e discuti-las durante a consulta. Considera-se que o determinante para procurar os serviços de saúde não é o sintoma mas aquilo que o doente «pensa» sobre o sintoma. ${ }^{3}$ Deverá ainda investigar possíveis motivos ocultos de consulta, que poderão constituir a verdadeira razão da procura dos cuidados, e aproveitar cada contacto para prestar cuidados oportunísticos. ${ }^{4}$ Os motivos de consulta são a senha para o acesso aos cuidados de saúde e, da interpretação que o utente e o MF deles fazem, resulta todo o processo subsequente da prestação desses cuidados. ${ }^{4}$ Deve ter-se em atenção que quando o doente procura o médico tem já um conjunto de ideias sobre aquele problema de saúde, a sua causa, consequências, gravidade e tratamentos desejáveis (pode até já ter consultado outros terapeutas que lhe terão oferecido os seus diagnósticos e os seus tratamentos). ${ }^{1}$ Fundamental é nunca esquecer o motivo, explícito ou oculto, que levou o doente a procurar os cuidados de saúde. Se este não for valorizado, se não forem exploradas e discutidas as ideias prévias do doente sobre o seu problema, corre-se o risco do MF se perder nos novos problemas por ele identificados e, consequentemente, o doente ficar insatisfeito com o encontro clínico, perdendo-se uma oportunidade de criar uma aliança. ${ }^{1}$

Como auxílio desta investigação, o MF pode fazer a gestão entre os conceitos de «illness» $\mathrm{e}$ «disease» ou «dolência» e «doença».

$\mathrm{A}$ «doença» $\mathrm{e}$ «dolência» não coexistem obrigatoriamente. Pode haver doença sem dolência e dolência sem doença. ${ }^{3}$ Neste caso, em relação à HTA, DM2 ou dislipidemia, uma vez que não tinha quaisquer sintomas, 
este doente não apresentava «illness» (dolência) e por isso mesmo não via necessidade de recorrer ao médico para vigilância ou tratamento. Considerava-se saudável e foi rotulado com um problema/uma doença diferente em cada consulta, com implicações importantes no seu padrão de vida. Deve-se tentar compreender como o doente perceciona os novos episódios de doença identificados pelo médico, a forma como vão afetar o seu comportamento e relacionamento com outras pessoas, o que está disposto a mudar e o que vai fazer para lidar com a situação. Atendendo sempre às suas dificuldades e ritmos, foi fundamental explicar o conceito médico de doença a este paciente para que percebesse a importância de cumprir a medicação e mantivesse consultas de vigilância. ${ }^{2} \mathrm{O}$ inverso também pode acontecer, o doente pode sentir-se doente e não objetivarmos doença. Estas queixas devem ser também valorizadas e exploradas. As duas situações devem ser tratadas de igual forma, através de uma atitude centrada no doente, para que se crie uma melhor relação médico-doente.

O conhecimento do sofrimento da pessoa, em todas as suas dimensões, exige conhecer as suas experiências individuais e subjetivas: sentimentos, pensamentos, emoções, receios e impacto na sua vida micro e macrossocial. Para este conhecimento será fundamental o MF manter uma escuta ativa, estando atento e descodificando o que lhe é transmitido pelo doente (por comunicação verbal e não verbal). ${ }^{3}$

Muitas vezes, os doentes, quando, aparentemente, não cooperam, estão a reagir não ao tratamento mas ao modo «como são tratados». ${ }^{4}$ Estabelecendo-se uma comunicação eficaz, a mensagem será mais bem entendida ou aceite pelo doente, que decide seguir ou não os conselhos do médico. Para tal é de extrema importância a discussão das agendas - do utente e do técnico de saúde - e a negociação com o doente do plano de tratamento proposto - explicar e envolver o paciente nas medidas a eleger, esclarecer todas as dúvidas colocadas, oferecer alternativas. Ao adotar uma atitude de negociação ativa com o doente tenta-se mudar o conceito de «adesão ao tratamento» para o de «aliança terapêutica». ${ }^{6}$ Pretende-se uma prestação de cuidados centrados na pessoa e baseados na confiança, de forma a fazer um percurso educacional do doente, com o objetivo de o responsabilizar e capacitar quanto à sua doen- ça, isto é, de promover o empowerment, fortalecendo assim a capacidade de decisão conjunta perante os problemas abordados no decorrer da consulta. ${ }^{5}$ Com o método clínico centrado no paciente destaca-se a singularidade de cada indivíduo, que é visto no seu contexto biopsicossocial e cultural, o que irá refletir-se na prestação de cuidados, tanto na forma como se apreende o que o doente diz como no modo como lhe é devolvida essa compreensão e se lhe expõe o plano mais adequado, de forma clara e ajustada à sua situação. Para tal, interessam ainda os medos, crenças e ideias associadas por cada doente a determinada doença/diagnóstico, que interferem também na forma como se deve abordar a experiência do «estar doente» e explorar os sentimentos desenvolvidos pelo paciente neste processo. ${ }^{5}$

Na análise da experiência da dolência devem ser considerados três estádios: consciencialização, desorganização e reorganização. ${ }^{3}$ A consciencialização é caracterizada pela ambivalência entre o desejo de saber a verdade e a recusa em aceitar que se está doente. De seguida instala-se a angústia e/ou depressão, como consequência da tomada de consciência da vulnerabilidade, fragilidade e sensação de perda de controlo sobre a sua vida. Isto é, a fase da desorganização. Quando o doente reúne as suas forças no sentido de encontrar novo sentido face à sua dolência, passamos ao estádio da reorganização. A capacidade de passar a esta fase irá depender da gravidade da doença e da qualidade das estruturas de suporte social, sobretudo das relações mais próximas, e do tipo de suporte prestado pelo seu médico. $^{3}$

O modelo clínico integrado, um desenvolvimento do método centrado na pessoa, combina várias abordagens: biomédica, psicossocial, centrada na pessoa, atenta ao médico e à relação médico-doente, e procura equilibrá-las e harmonizá-las, sem menosprezar nenhuma delas. ${ }^{5}$ Esta abordagem será essencial para evitar a má comunicação médico-doente, bem como os fenómenos de auto-medicação e a tão frequente má adesão terapêutica. E em última análise a insatisfação do doente com os cuidados prestados, ineficácia da consulta e o sentimento de frustração não só do doente mas também do MF.

Este deverá investir na compreensão destes conceitos e estar consciente que, quando aplicados na prática clínica, são uma mais-valia na melhoria dos cuida- 
dos prestados, conseguindo-se uma melhor relação médico-doente e satisfação com cada encontro clínico e, consequentemente, uma melhor gestão das doenças crónicas.

\section{REFERÊNCIAS BIBLIOGRÁFICAS}

1. Nunes B. Saúde e doença: a perspectiva do doente e a decisão de consultar. MGF2000. Disponível em: http://www.mgfamiliar.net/MMGF/ textos/11/1_texto.html [acedido em 05/10/2011].

2. Helman CG. Disease versus illness in general practice. J R Col Gen Pract 1981 Sep; 31 (230): 548-52.

3. Nunes JM. Comunicação em contexto clínico. Lisboa; Bayer Healthcare; 2007. Disponível em: http://www.mgfamiliar.net/itemgenerico/comunicacao-em-contexto-clinico [acedido em 25/07/2013].

4. Rodrigues J. Motivos de consulta e sua interpretação. MGF2000. http://www.mgfamiliar.net/MMGF/textos/12/11_texto.html [acedido em 25/07/2013].
5. Ramos $\vee$. A consulta em 7 passos - Execução e análise crítica de consultas em medicina geral e familiar. Lisboa:VFBM Comunicação; 2008.

6. Pereira J. Será possível uma nova medicina? Rev Crit Cien Sociais 1987; 23: 185-93.

\section{CONFLITO DE INTERESSES:}

As autoras declaram não ter conflito de interesses.

\section{ENDEREÇO PARA CORRESPONDÊNCIA}

Ana Cristina Pereira

Rua da Boa Nova, 325 - 4405-551 Valadares

E-mail: cristinafmpereira@gmail.com

Recebido em 31/10/2012

Aceite para publicação em 11/07/2013

Artigo escrito ao abrigo do novo acordo ortográfico.

\section{ABSTRACT}

\section{PATIENT-DOCTOR RELATIONSHIPS: AN ALLIANCE IN HEALTH CARE}

Introduction: The reasons that lead patients to seek health care, the value of symptoms, and their perception of problems depend on the personal history, cultural, socioeconomic and family context of the patient. Illness (the disease experience of the patient) and disease (the medical disease) are terms used to describe what the patient feels when he goes to the doctor and what he has when he returns home after the consultation. This case aims to highlight the importance of the presenting complaint and its exploration by the Family Physician.

Case Description: A 56 year-old unemployed man came to his first consultation in four years because of a lesion on his forearm, which has been present for five years. He was not receiving medication, did not smoke, and had moderate alcohol consumption. There was one visit recorded in 2007 with a diagnosis of hypertension. The blood pressure at the current visit was found to be elevated. In addition, a vegetative tumor was noted on his forearm. The patient agreed to renew follow-up, to perform the necessary tests, and accepted a referral to the dermatology clinic. A squamous cell carcinoma was diagnosed. The patient returned to clinic to obtain the results of his tests. A diagnosis of diabetes mellitus was suspected and confirmed. His blood pressure remained elevated and medication was prescribed.

Comment: The family physician must try to understand why patients choose to consult or delay consultation. Is there a fear of being labeled as a sick person? Is the social network weak? This patient, who considered himself healthy, was labeled with a different disease at each visit. The family physician should manage expectations, explore them, discuss them and negotiate with the patient so that care is more effective and better accepted by patients. This can have implications for adherence to treatment and patient satisfaction with the consultation.

Keywords: Patient-Doctor Relationship; Reason for Consultation; Disease; Illness. 